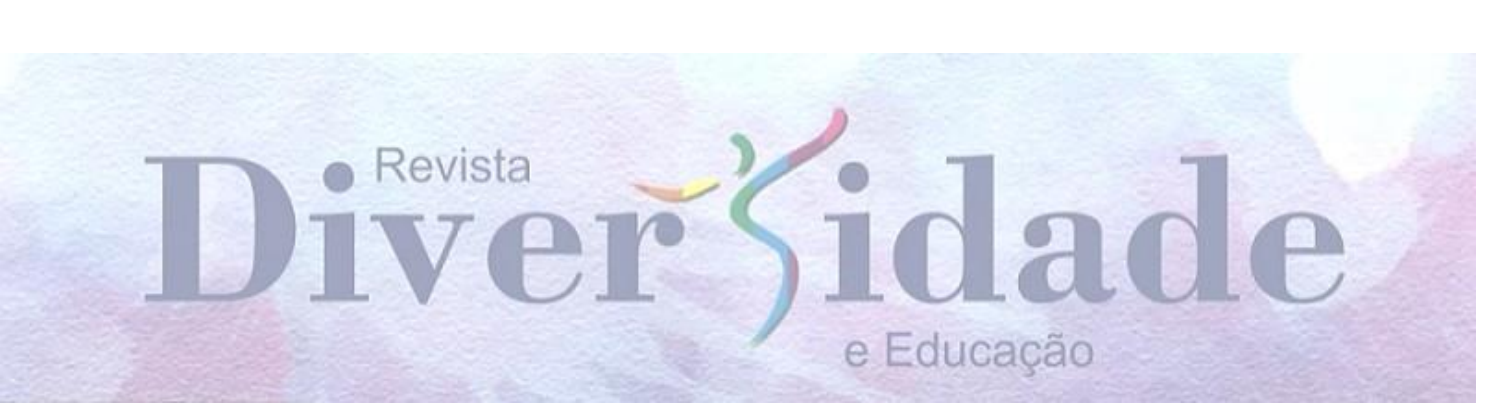

\title{
“AVE MARIA, CHEGOU A MACUMBEIRA!”: TENSÕES NO ENSINO DA HISTÓRIA E CULTURA AFRO-BRASILEIRA NA ESCOLA.
}

\author{
"AVE MARÍA, LLEGÓ LA HECHICERA!": TENSIONES EN LA \\ ENSEÑANZA DE LA HISTORIA Y CULTURA AFRO-BRASILEÑA EN LA \\ ESCUELA.
}

\section{"HAIL MARY, ARRIVED THE SORCERESS!": TENSIONS IN THE TEACHING OF HISTORY AND AFRO-BRAZILIAN CULTURE IN SCHOOL}

\author{
Roniel Santos Figueiredo ${ }^{1}$ \\ Marcos Lopes de Souza $a^{2}$
}

\section{RESUMO}

As discussões sobre história e cultura africana e afro-brasileira entraram no currículo escolar de maneira mais enfática após a lei 10639/2003. Contudo, tendo em vista o contexto histórico eurocêntrico que faz parte da constituição simbólica das escolas brasileiras, os agentes que se arriscam a dialogar sobre essas questões podem ser desaprovados. Portanto, esse trabalho apresenta e discute o processo de estigmatização vivenciado por Santos, uma professora, mulher negra e umbandista ao discutir história e cultura afro-brasileira na educação básica por meio do resgate dos aspectos culturais e de luta do povo negro. Nesse sentido, é perceptível que os discentes utilizam da religiosidade da professora para colocar em xeque a sua docência, gerando conflitos e abjeções.

PALAVRAS-CHAVE: Relações étnico-raciais. Docência. Relações de poder.

\section{RESUMEN}

Las discusiones sobre historia y cultura africana y afro-brasileña entraron en el currículo escolar de manera más enfática después de la ley 10639/2003. Sin embargo, teniendo en cuenta el contexto histórico eurocéntrico que forma parte de la constitución simbólica de las escuelas brasileñas, los agentes que se arriesgan a dialogar sobre esas cuestiones

1 Mestre em Relações Étnicas e contemporaneidade (PPGREC-UESB). Licenciado em Ciências Biológicas pela Universidade Estadual do Sudoeste da Bahia. Docente Assistente do Colegiado de Farmácia da Faculdade de Tecnologia e Ciências (FTC), Jequié, Bahia, Brasil.

2 Professor Doutor do Programa de Pós-Graduação em Relações Étnicas e Contemporaneidade (PPGREC) e do Programa de Pós-Graduação em Educação Científica e Formação de Professores (PPGECFP), ambos da UESB, campus de Jequié, Bahia, Brasil. 
pueden ser desaprobados. Por lo tanto, este trabajo presenta y discute el proceso de estigmatización vivido por Santos, una profesora, mujer negra y umbandista al discutir historia y cultura afro-brasileña en la educación básica por medio del rescate de los aspectos culturales y de lucha del pueblo negro. En ese sentido, es perceptible que los discentes utilizan la religiosidad de la profesora para poner en jaque su docencia, generando conflictos y abyecciones.

PALABRAS-CLAVE: Relaciones étnico-raciales. Docencia. Relaciones de poder.

\section{ABSTRACT}

Discussions on African and Afro-Brazilian history and culture entered the school curriculum more emphatically after law 10639/2003. However, in view of the Eurocentric historical context that is part of the symbolic constitution of Brazilian schools, agents who risk dialogue about these issues can be disapproved. Therefore, this work presents and discusses the process of stigmatization experienced by Santos, a teacher, black woman and umbandista in discussing Afro-Brazilian history and culture in basic education through the rescue of the cultural aspects and struggle of the black people. In this sense, it is noticeable that the students use the teacher's religiosity to challenge their teaching, generating conflicts and abjections.

KEYWORDS: Ethno-racial relations. Teaching. Power relations.

\section{Introdução}

O estudo sobre história e cultura afro-brasileira e africana se tornou obrigatório no ensino fundamental e médio nas escolas públicas e particulares com a lei 10.639/2003 que alterou a Lei de Diretrizes e Bases da Educação Nacional 9394/1996. Segundo o texto dessa lei, deve ser abordada "a história da África e dos africanos, a luta dos negros no Brasil, a cultura negra brasileira e o negro na formação da sociedade nacional, resgatando a contribuição do povo negro nas áreas social, econômica e política pertinente à história do Brasil" (BRASIL, 2003). Dessa forma, essa legislação reiterou a necessidade de se trabalhar com a história dos grupos marginalizados que foram silenciados no decorrer da história educacional do país.

Essa conquista configura-se como resultado de esforços do movimento social negro ao buscar novos modelos educativos que discutam a diversidade cultural e étnica para além, simplesmente, de sua pluralidade, percebendo os esforços e as lutas envolvidas nesse contexto de tensão e disputas étnicas que estão presentes desde a colonização. Ou seja, embora essa lei seja uma política educacional desenvolvida pelo Estado, é resultante dos esforços da comunidade civil (ALVES; GOMES, 2013). 
Nesse sentido, esse trabalho apresenta e discute as relações escolares vivenciadas por uma professora, mulher negra e umbandista ao discutir história e cultura afro-brasileira na educação básica.

\section{Santos, uma mulher de Santo.}

A professora que protagoniza as cenas narradas nesse trabalho se reconhece como mulher negra, umbandista e periférica. Com 58 anos de idade e 35 anos de trabalho na educação básica do estado da Bahia. A professora recebe no decorrer desse texto o pseudônimo "Santos", nome fíctício escolhido por ela. Esse nome é comum na forma de sobrenomes, de origem portuguesa e que geralmente era dado às pessoas nascidas no dia $1^{\circ}$ de novembro - dia de todos os santos. Outros/as pesquisadores/as defendem que a popularização desse nome se deu após a abolição da escravatura, quando diversas pessoas que foram libertas do regime escravocrata receberam este sobrenome por residirem na Bahia de Todos os Santos (MOTOMURA, 2017). Na Bahia é comum dizer que as pessoas que cultuam os orixás são "povo de santo". Assim, esse texto diz de uma professora que é "de santo" e que vivencia a sua espiritualidade por intermédio dos santos, orixás e entidades e que por apresentar esse perfil de gênero e étnico, além de discutir cultura afro-brasileira na educação básica foi diversas vezes contestada, questionada e desqualificada na sua atividade profissional, sobretudo, pelos discentes. Os excertos narrados nesse trabalho foram construídos a partir de entrevistas realizadas com a professora Santos para a dissertação produzida pelo primeiro autor.

\section{"Eu só fiz responder para eles assim: a macumba está ótima. Aí ele arregalou os olhos para mim assim... e eu disse: a macumba é boa!": a escola enquanto campo de disputa.}

Um dos argumentos mais utilizados para justificar as práticas discriminatórias, de modo geral, é a falta de conhecimento como se as pessoas não tivessem contato com os seus focos de discriminações. Ou seja, é como se o fato de uma pessoa nunca ter ido a um espaço de cultos de matriz africana fosse sinônimo de não ter nenhum contato ou informação sobre esses espaços religiosos e, por isso, fosse justificada a repulsa e ações de cunho preconceituoso. Por outro lado, os/as alunos/as que tratam a professora Santos de maneira desrespeitosa possuem conhecimento sobre os terreiros, sobre as práticas das religiões de matriz africana e utilizam desse saber para, de alguma forma, 
"competir" pelo poder com essa professora. Afinal, diversos são os meios em que as informações sobre as religiões de matriz africana são veiculadas, geralmente a partir da perspectiva do exótico, cômico, estranho e supersticioso. Na maioria das vezes essas abordagens são marcadas pela presença de "piadas" e "brincadeiras". Essas situações de conhecimento das religiões de matriz africana são apresentadas nesses três relatos feitos por Santos:

Estava acontecendo os jogos e estava passando as músicas que desfaz da mulher. Aí eu fui chamar a atenção dos meninos, do pessoal que estava controlando a música. Eram os alunos mesmos. Aí chamei uma vez, chamei duas. Aí fiquei de um lado observando. Quando de repente eu olho e tá um menino do lado: "O macumbeiro faz assim! O macumbeiro faz assim!'(dançando). Isso inclusive em uma sexta-feira e eu estava com blusa branca. Aí ele fazia o gesto de como estivesse dançando no terreiro. Ele dançava e olhava para mim e eu olhava para ele assim. E todo mundo olhando para mim para ver a minha reação, mas aí eu respirei e falei assim para mim mesma: "Eu não vou reagir, eu não vou fazer nada!". Por que o que eu poderia dizer nesse momento? Eu fiquei quieta e aí um aluno foi e disse assim: "Oxe rapaz, o que é isso?" - Reclamou com ele. Aí ele terminou parando (Professora Santos).

Acho que foi em uma segunda-feira. Estavam todos os alunos na área, né? E aí uma colega pediu para que eu fizesse uma oração. Quando eu peguei o microfone um aluno disse: "Que ruflem os tambores". E aí começou bater na mesa assim (como se tocasse o instrumento de percussão), indiretamente eu entendi o porquê ele falou, né? $\mathrm{Na}$ verdade assim, naquele momento fiz de conta que não estava ouvindo nada, fui indiferente a fala dele. Por isso acontecer sempre, sempre... eu fui indiferente, mas intimamente eu me senti angustiada. Assim... A gente se sente assim, como se fosse algo diferente, tá entendendo? De imediato, naquele momento, dentro de mim, lá dentro de mim, eu fiquei triste, por que eu entendi que aquilo era falta de respeito, era intolerância, por eles saberem qual era a minha religião e por eu também discutir a cultura afro, porque só em discutir a cultura afro, muito deles já acham que é macumba, que é coisa demoníaca. Mas eu não deixei transparecer que esse questionamento dele tinha me angustiado. Fiz a oração, encerrei e aí acabou (Professora Santos).

A semana passada mesmo pela manhã eu estava cá embaixo no anexo da escola. Aí os meninos estavam fora da sala e eu disse: "O que vocês estão fazendo fora da sala? Vamos, vamos, vamos!" Aí um menino virou e disse assim: "Eh professora, e a macumba?". Eu só fiz responder para eles assim: "a macumba está ótima!". Aí ele arregalou os olhos para mim assim e eu disse: "a macumba é boa!". Aí ele foi para sala eu também não disse nada e ele também não perguntou nada. [...] Então acontece dessas coisas, porque eu sou muito visada na escola (Professora Santos).

Nas três situações narradas é possível perceber que as interpelações realizadas 
pelos discentes visam o silenciamento da professora. Eles desejavam que ela se calasse, que de alguma forma se submetesse a autoridade dos discursos evocados por suas vozes. Na primeira narrativa, o aluno agiu afrontosamente após a professora o reclamar. A docente ainda associou essa atitude ao fato de ela estar usando branco em uma sextafeira dia consagrado pelo povo de santo ao orixá Òsàlá (Oxalá), por ser considerada uma divindade da cor branca, chamada de funfun na cultura yorubá. Após ser impelida, a professora se manteve calada por não perceber nenhuma possibilidade de intervenção, contudo, outro aluno repreendeu a atitude do colega, mostrando que as vozes que a discriminam não são unívocas. Existem também vozes que apoiam a professora e elas são importantes nesse processo de significação das práticas pedagógicas de Santos.

$\mathrm{Na}$ segunda situação o aluno traz o tambor enquanto elemento religioso para mais uma vez demarcar a religiosidade da professora em um momento em que ela foi convidada a fazer uma oração, deslegitimando ela enquanto pessoa capaz de orar, de ter um vínculo de proximidade com Deus. Assim, é possível perceber que os/as discentes, muitas vezes têm conhecimento de aspectos, instrumentos e práticas das religiões de matriz africana e utilizam deles para constranger e silenciar a professora Santos.

$\mathrm{Na}$ terceira situação, a professora, diferentemente das outras narrativas, responde ao aluno dizendo que a macumba está boa, que ser macumbeira é ótimo. Nesse momento a professora desestabiliza a lógica empreendida pelo aluno, em que ser macumbeiro/a é uma ofensa e que a professora deveria se sentir inibida e acuada diante de "acusações" com esse teor. Naquele momento a professora rompeu, ao menos temporariamente, com o estigma. É como se dissesse "sou macumbeira sim e não há problema nenhum com isso". Ela positivou o termo e isso gerou surpresa por parte do aluno por não esperar aquilo, como ela disse, ele "arregalou os olhos". A positivação de termos usados pejorativamente é um dos achados da teoria queer, pois o próprio nome da teoria é um termo inglês usado para ofender as pessoas homossexuais. Como aponta Judith Butler: "Queer adquiere todo su poder precisamente a través de la invocación reiterada que lo relaciona con acusaciones, patologías e insultos" (BUTLER, 2002, p. $58)$.

Ou seja, ser queer é estar à/na margem, mas não entender isso como algo ruim que deve ser eliminado, problematizando as posições sociais sem perseguir o centro como foco, mas transgredindo os limites, as fronteiras e vivendo a ambiguidade (LOURO, 2013). Um ponto importante e que conecta duas das situações vivenciadas pela professora é a presença as atitudes discriminatórias dos alunos ocorrerem após a 
professora os reclamar, ou seja, exercer sobre eles a autoridade que a posição docente lhe confere. Nesse sentido, é importante perceber o quanto essas discriminações dialogam com as posições que os sujeitos ocupam na estrutura escolar. Portanto, é importante compreender que essas discriminações estão entrelaçadas às relações de poder que perpassam fortemente o contexto educacional.

Para Foucault (1989) só há relação de poder quando há resistência, quando ela inexiste, há apenas uma relação de dominação. É importante, nesse contexto, salientar que o poder permeia todas as faixas sociais e todos os grupos. Com base em Foucault, a compreensão das relações relatadas pela professora embrenham os contextos históricos, sociais e culturais com os mecanismos de poder que geram regimes de saberes e verdades. Para tanto, destaca-se, nessa situação, a professora e os alunos como duas agências diferentes (discente e docente) que, de alguma forma, mantém uma relação perpassada por poder. Assim, partindo dessa análise, a nomenclatura utilizada pelos/as discentes para designar a professora funciona como mecanismo de disputa de poderes, uma forma de desestabilizar a posição que hierarquicamente a escola the confere ao produzi-la como professora que, assim como os demais "cargos" (diretor/a, alunos/as, funcionários/as etc.), constitui uma posição de sujeito na hierarquia da comunidade escolar. Essa compreensão possibilita a percepção que Santos, ao entrar na escola não é apenas a pessoa, mulher e mãe Santos, ela é a professora Santos e esse título vem carregado de responsabilidades e ações que são "esperadas" para uma professora, inserindo-a, dessa forma, no grupo constitutivo de docentes. Uma vez que a linguagem constitui o sujeito, nesse espaço-tempo Santos é construída enquanto professora.

E ser professora, no contexto sociocultural, é servir como inspiração para os/as seus/suas alunos/as, um verdadeiro exemplo de conduta e moral (LOURO, 2007). No entanto, ao lerem a professora como macumbeira e perceberem esses aspectos como algo ruim, a veem como uma pessoa que faz mal a sociedade, ou ao menos, que tem potencial para isso já que frequenta terreiros e participa de rituais que na leitura deles são "macabros". Ao polarizarem essas duas identidades os discentes agem como se esses dois aspectos fossem inconciliáveis, ou seja, ela não pode ser, ao mesmo tempo, macumbeira e professora.

Após discorrer sobre a tensão que existe nessa relação de saber/conhecer e poder, dois questionamentos ganham força nessa discussão: por que os/as alunos/as utilizam a religiosidade afro-brasileira da professora para ofendê-la e desestabilizar a sua identidade docente? Quais os discursos que sustentam essas práticas 
discriminatórias?

Rastrear vestígios históricos que se somam na forma em que esses discursos foram/são construídos constitui um exercício importante. De acordo com Brandão (1986), no processo de escravidão durante a colonização no Brasil, a população negra trazida da Àfrica era batizada no porto aonde chegava, devendo receber um nome branco e cristão e aprender a falar a língua do colonizador. Ao mesmo tempo, não era permitido o culto aos seus deuses e às entidades espirituais. Eles e elas eram obrigados/as a cultuar ao Deus venerado pelos senhores ao qual "pertenciam". As diferenças precisavam ser minimizadas para que a relação de poder fosse mais efetiva e a religião foi utilizada como uma forma de exercer o controle. A liberdade de crença só foi alcançada no Brasil, após um salto histórico para o final do século XIX, baseada em valores republicanos. Nesse mesmo período foi reconhecida legalmente a laicidade do estado, havendo, portanto, a separação entre Igreja (católica) e estado. Esse marco foi importante para o reconhecimento da pluriconfessionalidade religiosa no país. No entanto, os conflitos e desigualdades não foram resolvidos apenas com a legislação, pois no imaginário social permanecem as ideias valorativas sobre as religiões produzidas no decorrer da história. Dessa forma, as discriminações ainda ocorrem e colocam as religiões não hegemônicas como secundárias e menos importantes (DUQUE, 2014).

Nesse processo de secundarização das religiões de matriz africana incorre a demonização das formas em que os rituais dessas religiões são realizados, gerando medo, repúdio, ódio e discriminação por parte de uma parcela significativa da sociedade. Mesmo em se tratando de religiões sincréticas, essas ainda são consideradas menos valiosas e importantes quando comparadas com outras. No que refere ao contexto escolar, esses discursos são retomados e, muitas vezes, utilizados como “armas" na destituição da professora enquanto uma profissional capaz de dialogar sobre as questões relacionadas à história e cultura afro-brasileira.

\section{Considerações Finais}

O espaço escolar é um rico campo para as discussões das diferenças tendo em vista a diversidade cultural presente. Contudo, essas discussões geram confrontos em contextos marcados pela presença do discurso hegemônico que secundariza e silencia a diferença. A professora Santos foi inquirida durante diversos momentos a se posicionar por ser mulher negra, umbandista e falar sobre história e cultura afro-brasileira. Ao 
trazer elementos da sua vivência religiosa "dissidente" para a educação, os discursos de ódio se levantaram contra a professora, fazendo da escola uma arena de disputa. Apesar desse processo, é necessário que existam pessoas engajadas como a professora Santos que mesmo com toda a estigmatização não abriu mão de lutar pelo que acredita e de perceber a escola como espaço importante para as discussões das diferenças.

\section{Referências:}

ALVES, A. N. R; GOMES, N. L. Contribuições da lei 10.639/03 no autorreconhecimento quilombola: estudo de caso na comunidade de Barro Preto (MG). In: OLIVEIRA, J. M. de (org). Interfaces das africanidades em educação nas Minas Gerais. Juiz de Fora: Editora UFJF, 2013, p. 121-138.

BRANDÃO, C. R. Identidade e Etnia. Editora Brasiliense, 1986.

BRASIL. Ministério da Educação. Diretrizes Curriculares Nacionais para a Educação das Relações Ético-Raciais e para o Ensino de Historia e cultura Afro-brasileira. Brasília: MEC, 2003.

BUTLER, J. Críticamente subversiva. In: JIMÉNEZ, Rafael M. Mérida. Sexualidades transgressoras. Una antología de estudios queer. Barcelona: Icária editorial, 2002.

DUQUE, T. Religiosidades e Educação Pública. In: MISKOLCI, R. JÚNIOR, J. L. (org.) Diferenças na Educação: outros aprendizados. São Carlos: EdUFSCar, 2014, 253 p.

FOUCAULT, M. Microfísica do poder. Tradução de Roberto Machado. $8^{\mathrm{a}}$ ed. Rio de Janeiro: Graal, 1989, pp. 179/191.

LOURO, G. L. Pedagogias da sexualidade. In: LOURO, G. L. (org.). O corpo educado: pedagogias da sexualidade. 2. ed., $3^{a}$ reimpressão, Belo Horizonte: Autêntica, 2007, p. $35-82$.

LOURO, G. L. Um corpo estranho: Ensaios sobre sexualidade e teoria queer. 2.ed.Belo Horizonte: Autêntica Editora, 2013.

MOTOMURA, M. Por que tem tanto "Silva” no Brasil?. Disponível em: http://mundoestranho.abril.com.br/cultura/por-que-tem-tanto-silva-no-brasil/. Acesso em 07 de dezembro de 2017.

Recebido em Agosto de 2018. Aprovado em Setembro de 2018. 